We present an empirical exploration of peer network mechanisms that encourage antisocial behavior in early adolescents. We apply SIENA, a network modeling methodology that addresses developmentally changing, statistically dependent interpersonal friendships.

\title{
Early Adolescent Antisocial Behavior and Peer Rejection: A Dynamic Test of a Developmental Process
}

\author{
John M. Light, Thomas J. Dishion
}

Evidence supports the hypothesis that adolescent peer groups play a significant role in the genesis of youth antisocial behavior (Dishion \& Patterson, 2006). A longstanding interest in research focused on individual differences in teen exposure to deviant peer groups is the notion that high-risk youth aggregate because of their common rejection within social contexts, such as the school environment (Cairns, Neckerman, \& Cairns, 1989; Dodge et al., 2003; Gifford-Smith, Dodge, Dishion, \& McCord, 2005; Olson, 1992). We refer to this dynamic process as the confluence hypothesis (Dishion, Patterson, \& Griesler, 1994). The fundamental dynamics are generated by two interrelated processes, selection and influence:

1. Youth at risk for antisocial behavior tend to affiliate differentially with each other (selection).

2. These affiliations then increase the risk for higher frequency and severity of such behavior (influence).

Two sets of findings provided a major impetus to the surge in peer relationship research in the 1980 s. First, investigators recognized that peer

NHH grants DA018760-02 and DA13773-05 supported the work on this chapter. We thank Christine Cody for editorial support. 
rejection and isolation in childhood were associated with poor adult outcomes (Hartup, 1992). Second, studies showed that peer rejection was a reliable outcome of childhood aggressive behavior (Coie \& Kupersmidt, 1983; Dodge, 1983), which furthermore predicted continued aggression several years later (Dodge et al., 2003). Yet this plethora of work provided no convincing case that peer rejection had a causal role in the etiology and course of problem behavior. If peer rejection is causal, what are the mechanisms?

Advances on this issue occurred by crossing boundaries between two disciplines: criminology and developmental psychology. Those studying adolescent delinquency recognized such behavior as a "team activity" (Gold, 1970). Later, systematic longitudinal studies of nationally representative samples revealed deviant peers to be a strong correlate of adolescent delinquency (Elliott, Huizinga, \& Ageton, 1985). Considering both developmental and sociological literature led to a paradox: If delinquent youth face peer rejection and lack social skills, why do they belong to normal-sized peer groups (see Farmer \& Hollowell, 1994; Farmer, Van Acker, Pearl, \& Rodkin, 1999) encouraging their behavior?

The confluence hypothesis emerged to account for the paradox. The idea is simple: deviant peer groups form among mutually rejected youth, who adapt by forming a unique group with a deviant set of mutually influential norms (Dishion et al., 1994). In earlier studies consistent with this hypothesis, we found that peer rejection covaried with more extreme measures of deviant peer involvement in early adolescence. Dishion, Nelson, and Yasui (2005) found sixth-grade peer rejection combined with academic failure to predict eighth-grade male gang involvement, and Rodkin, Farmer, Pearl, and Van Acker (2000) found antisocial males to be most typically (though not invariably) disliked by others.

These studies, while compelling, fell short of a dynamic test of the confluence hypothesis. Primarily the analyses did not consider network embedding. Various factors besides social influence among rejected youth could explain that rejection rates in one year correlate with gang formation two years later. For example, neighborhood could affect both rejection and future gang affiliation. However, analyses by Dishion, Nelson, and Kavanagh (2003) suggested an important principle: each school creates its own peer ecology. Hence, rejection conlluence dynamics may vary among schools and need examination within schools. We seek to advance this work by apply. ing a relatively new modeling technique that applies panel-data logic (Kessler \& Greenberg, 1981) to peer social ecologies (Snijders, Steglich, Schweinberger, \& Huisman, 2007), which we describe in more detail here.

The study of peer group selection and influence effects has benefited from increased reliance on social network methodology. In network studies, we might measure individual-level peer affiliations by asking each member of a relatively closed social group (members of one grade at a school) who their friends are. A number of variations on this procedure are possi- 
ble (Marsden, 2005). This yields a complete network, that is, a map showing precisely who links to whom. The network approach has two major advantages over other less-specialized methodologies. The first stems from evidence that youth overestimate similarity between themselves and their friends with respect to antisocial behavior (Bauman $\&$ Fisher, 1986; Prinstein \& Wang, 2007). This can lead to biased estimates of selection and influence effects (Ennett \& Bauman, 1994). In network studies, the data point to the friends and the friends' self-reports give a truer assessment of behavior. A second advantage is that networks properly represent "complete" embedding of individuals - that is, their indirect as well as direct relationships - thus reflecting not only an actor's own friends but also the larger context in which this peer group is located.

However, social network modeling presents some methodological challenges. The object is to predict changes in an array of interrelated links, which is beyond the scope of standard statistical methods. Moreover, because network-embedding measures for individuals usually have their basis in overlapping subgroups (Snijders, 2005), individual-level network data are inherently dependent. Ignoring data dependency, even of ostensibly minor magnitude, can produce unpredictable biases in analyses (Kenny \& Judd, 1986; Murray \& Hannan, 1990). Multilevel modeling is of limited value for longitudinal analysis of such data, moreover, because dependencies change between waves.

Snijders and colleagues developed a statistical modeling methodology, SIENA, for retaining advantages of network methodology while addressing these challenges (Snijders, 2005; Snijders, Steglich \& Schweinberger, 2006). SIENA is an open-source program, available free with documentation at http:/stat.gamma.rug.nl/stocnet. We describe it further below.

We applied SIENA to test a set of specific hypotheses derived from the social learning-based account of antisocial deviant peer processes outlined above. These hypotheses focused on the parts of antisocial peer dynamics that make the process, by virtue of creating a causal feedback loop.

1. Antisocial behavior predicts peer social marginalization.

2. Marginalized (rejected) youth tend to affiliate disproportionately with each other.

3. Changes in antisocial behavior are proportional to the level of antisocial behavior of one's direct peers.

In this model, antisocial behavior and social status enter as both cause and effect; thus, the model has "endogenous dynamics" (Butner, Amazeen, $\$$ Mulvey, 2005), that is, change in system properties over time in the absence of external forces. Together, the above hypotheses posit that early antisocial behavior affects peer affiliations and those affiliations subsequently affect antisocial behavior, further influencing peer affiliations, and so on. 


\section{SIENA Models of Social Ecologies}

We may represent friendship linkages at any time as a social network (Wasserman \& Faust, 1994). To capture change, we imagine a series of snapshots representing the state of each possible friendship tie at each point. Conceptual and analytical problems posed by time series of social networks are immediately apparent in, for example, the sheer number of possible ties. In a typical U.S. middle school of 300 students, some 90,000 relationships are possible (counting ties in both directions). Modeling their collective change over time is the rather daunting primary objective of longitudinal network analysis.

In contrast to typical statistical modeling, SIENA takes a decisionsimulation approach by randomly choosing network members in simulated continuous time. After an actor's selection, the actor may choose to change a network tie, adding a new link or deleting an existing one. The probability of making a specific choice depends on a set of user-specified effects. Many effects are possible, as discussed below. The decision process may further include simulated choices to change a particular behavior, and behavioral decisions may be effect-driven. Each effect has a parameter associated with it, the size and sign of which determine the effect's magnitude and direction. Statistically sophisticated readers will recognize the decision simulation as a Markov process; hence, Monte-Carlo (MCMC) procedures can provide parameter estimates. Each run takes parameter values from the last one, incrementally changing them to fit the data better until further changes to parameter values do not materially improve model fit. SIENA supports several fit criteria, but we used Method Of Moments because of its superior execution speed. Iterative procedures also provide estimated standard errors (Snijders, 2001, 2005; Snijders et al., 2007).

SIENA allows three types of predictors of link changes. The first is structural, such as out-degrees (unidirectional ties), reciprocity (2-way ties), transitivity (3-way link closure), among others (Wasserman \& Faust, 1994). The second comprises measured properties of edges or pairs of individuals in the network, such as geographical distance between individuals or membership in one organization. Finally, characteristics of individuals themselves may serve as predictors of link change. These different classes of predictors can interact. The result is a model of tie formation and dissolution probability. We interpret the model much like an ordinary regression model with main and interaction effects. Significance of individual effects are obtained with $t$-ratios.

SIENA also models change in user-specified characteristics (usually a behavior) hypothesized to depend on aspects of an actor's network embedding (number of direct or reciprocated linkages, the average behavior of those linkages, and others; Snijders et al., 2007). This way, the SIENA-based actor decision model reflects a mutual relationship between behavior and social relationships posited by the rejection confluence idea, that is, they affect each other over time. 


\section{Sample and Methods}

Subjects. Subjects were 1,289 public middle-school students from eight schools in one district in suburban Oregon. The final sample represents 74 percent recruitment, with 82 percent completing all three waves of assessment, conducted during the fall of sixth, seventh, and eighth grades. The sample was 45 percent male, 55 percent female, primarily European American ( 79 percent), and with a small percentage of Latino students ( 4.5 percent), representative of the study community. The final recruitment rate by wave and school varied from 58 to 81 percent, with an unweighted mean of 70 percent. Further procedural details are available elsewhere (Stormshak, Dishion, Light, \& Yasui, 2005).

\section{Measures}

Social Networks. We defined the networks based on friendship nominations. Upon request, students named three best friends from a class list. We treated a nomination as a direct tie, one that another student may or may not reciprocate.

We performed analyses on directed (asymmetrical) network data, using twenty-four adjacency matrices to represent the peer networks of our respondents over time. For each school $\mathrm{k}=1, \ldots, 8$ and each wave $\mathrm{t}=1,2,3$ (corresponding to sixth through eighth grades), nominations were converted to asymmetric $n_{k t}$ (number of students per class) $\times n_{k t}$ matrices, with the $(\mathrm{i}, \mathrm{j})$ th entry $=1$ if individual i nominated individual $j$ on the relationship criterion, and 0 otherwise. Table 6.1 shows the wave-specific numbers for each school.

Rejection (Social Status). Students also nominated those individuals in their grade as those "with whom you would not like to be in a group." We took the total number of such nominations as a proportion $(\times 100$, rounded to the nearest integer, a requirement for fitting SIENA models) of the total number in the network (total participants) as a rejection score for each individual.

Antisocial Behavior. The Oregon Healthy Teens Survey (Biglan, Metzler, $\&$ Ary, 1994) provided a measure of problem behavior. We used the Antisocial Behavior scale for these analyses (alpha $=0.84$ ), including self-reports of lying, stealing, vandalism, violence, and others. Respondents reply on a 0-5 scale ("never" to "more than 20 times").

Model Testing Protocol. SIENA models normally include standard network structure effects: outdegree, reciprocity, and some form of transitivity. Outdegree is the number of individuals the respondent selects as a friend. Reciprocity is the tendency for individuals to extend more ties if they are reciprocated (that is, if individual $j$ also selects individual i). Transitivity involves "closure" of triads in the network over time; if A links with B and $B$ links with $C$, then more likely $C$ will eventually link with $A$. Several specific network statistics reflect transitivity (see Snijders, 2005). We found that "actors at distance 2" (D2) was the most reliable triad closure effect (the fewer such structures there are, the more likely it is that an A-B-C linkage 
Table 6.1. Descriptive Statistics for School Networks

\begin{tabular}{|c|c|c|c|c|c|c|c|c|}
\hline School & Wave & $\begin{array}{c}\text { Network Size } \\
\text { Subjects }\end{array}$ & $\begin{array}{c}\text { Network Total } \\
\text { Grade }\end{array}$ & Percentage & $\begin{array}{c}\text { Antisocial Behavior } \\
\text { Mean(SD) }\end{array}$ & $\begin{array}{c}\text { Antisocial Behavior } \\
\text { Maximum }\end{array}$ & $\begin{array}{c}\text { \#More } \\
\text { Antisocial Behavior }{ }^{1} \\
(t-1) \rightarrow t\end{array}$ & $\begin{array}{c}\text { \#Less } \\
\text { Antisocial Behavior }{ }^{1} \\
(t-1) \rightarrow t\end{array}$ \\
\hline \multirow[t]{3}{*}{1} & 1 & 111 & 182 & 61 & $.15(.27)$ & 2.0 & - & - \\
\hline & 2 & 119 & 196 & 61 & $.20(.39)$ & 2.3 & 21 & 14 \\
\hline & 3 & 119 & 190 & 63 & $.32(.35)$ & 1.9 & 51 & 10 \\
\hline \multirow[t]{3}{*}{2} & 1 & 94 & 144 & 62 & $.14(.35)$ & 2.6 & - & - \\
\hline & 2 & 104 & 143 & 73 & $.19(.40)$ & 2.1 & 17 & 10 \\
\hline & 3 & 101 & 157 & 64 & $.34(.44)$ & 2.4 & 50 & 39 \\
\hline \multirow[t]{3}{*}{3} & 1 & 123 & 171 & 72 & $.17(.41)$ & 2.4 & - & - \\
\hline & 2 & 132 & 192 & 69 & $.23(.39)$ & 1.1 & 26 & 10 \\
\hline & 3 & 135 & 192 & 70 & $.48(.59)$ & 3.0 & 64 & 11 \\
\hline \multirow[t]{3}{*}{4} & 1 & 115 & 182 & 63 & $.24(.50)$ & 3.3 & - & - \\
\hline & 2 & 113 & 173 & 65 & $.26(.39)$ & 1.8 & 25 & 19 \\
\hline & 3 & 137 & 180 & 76 & $.43(.39)$ & 2.1 & 57 & 17 \\
\hline \multirow[t]{3}{*}{5} & 1 & 131 & 167 & 78 & $.21(.39)$ & 2.3 & - & - \\
\hline & 2 & 133 & 164 & 81 & $.30(.50)$ & 1.8 & 31 & 22 \\
\hline & 3 & 121 & 156 & 78 & $.58(.52)$ & 3.7 & 77 & 8 \\
\hline \multirow[t]{3}{*}{6} & 1 & 149 & 103 & 73 & $.16(.38)$ & 2.3 & 一 & - \\
\hline & 2 & 145 & 106 & 70 & $.13(.24)$ & 1.1 & 14 & 17 \\
\hline & 3 & 1.53 & 204 & 75 & $.40(.43)$ & 1.7 & 70 & 8 \\
\hline \multirow[t]{3}{*}{7} & 1 & 200 & 253 & 79 & $.11(.26)$ & 2.1 & - & $\ldots$ \\
\hline & 2 & 198 & 247 & 80 & $.14(.30)$ & 1.8 & 36 & 19 \\
\hline & 3 & 195 & 253 & 77 & $.41(.50)$ & 3.9 & 101 & 10 \\
\hline \multirow[t]{3}{*}{8} & 1 & 85 & 146 & 58 & $.17(.28)$ & 1.3 & - & - \\
\hline & 2 & 116 & 161 & 72 & $.20(.40)$ & 2.2 & 14 & 11 \\
\hline & 3 & 107 & 155 & 69 & $.40(.51)$ & 3.3 & 54 & 7 \\
\hline
\end{tabular}

${ }^{1}$ Number of individuals increasing or decreasing their antisocial behavior between pairs of waves.

${ }^{2}$ Scale range $0-5$. 
chain has "closed" through the addition of an A-C link, or the chain itself has disintegrated; hence D2 is essentially an inverse-transitive structure). In some analyses, network structure effects are substantively important, but here they were simply control covariates, included in all models reported below, along with gender.

Testing Confluence. Using SIENA, we estimated separate models for each of the eight schools, based on our experience that school social ecologies may have unique dynamics (Stormshak et al., 1999). We examined three confluence-based hypotheses. With three waves of data, we estimated lag-one effects pooled across the two consecutive two-year periods (grades 6 through 7 and grades 7 through 8 ). Two of these hypotheses pertain to friendship formation and dissolution (selection): (1) antisocial youth tend to face rejection by their peers, and (2) rejected youth tend to affiliate with each other. To test for these statistical patterns, we included two model effects: Antisocial Behavior Alter (AB-Alter) and Rejection Similarity (Rej Sim). We hypothesized friendship ties were less likely when the Alter had higher levels of antisocial behavior; therefore, we expected this effect to be negative. In contrast, we expected the Rej Sim to be positive; individuals are more likely to form ties with others of similar rejection status. The third hypothesis predicted a positive association between a student's antisocial behavior at time $t$ and that of nominated friends at time $t-1$ (influence).

\section{Results}

Table 6.1 shows mean antisocial scores by school and wave that increase generally from sixth through eighth grades. The increase from seventh to eighth grade is greater than from sixth to seventh. There are obviously differences in average antisocial behavior between schools (largest in school 5 , smallest in school 7).

Table 6.1 also shows changes in antisocial behavior between the two pairs of waves. A substantial percentage (about 25 to 50 percent) report behavior changes between waves, with most increasing rather than decreasing. Such change is common in early adolescence. Overall, about 1 to 1.5 percent of ties change between waves, the low percentage reflecting mainly the (typical) sparseness of friendship networks. As a network of 150 individuals includes over 20,000 possible one-way linkages, there are hundreds of link changes evident in the data across each pair of waves. Our models were designed to account for these changes.

Table 6.2 presents final SIENA models estimated for each of the eight schools. All models included four basic structural effects: outdegree, reciprocity, distance-2, and gender similarity (rate effects were modeled but are not presented). For the purpose of this study, we treated these effects as nuisance variables, included to ensure confluence-related effects were not confounded with other well-known influences on friendship tie formation. Table 6.2 shows nearly all these effects to be statistically significant for all 
Table 6.2. SIENA Model Results for "3 Best Friend" Linkages

\begin{tabular}{|c|c|c|c|c|c|c|c|c|}
\hline Effects & School 1 & School 2 & School 3 & School 4 & School 5 & School 6 & School 7 & School 8 \\
\hline \multicolumn{9}{|l|}{ Tie formation covariates } \\
\hline Outdegree & $-2.4 *(0.2)$ & $-2.0^{*}(0.1)$ & $-2.0 *(0.2)$ & $\left.-1.6^{*} 0.2\right)$ & $-1.9 *(0.1)$ & $-2.3 *(0.6)$ & $-1.7 *(0.3)$ & $-1.9^{*}(0.3)$ \\
\hline Reciprocity & $2.4 *(0.2)$ & $2.3 *(0.1)$ & $2.4 *(0.1)$ & $2.7^{*}(0.1)$ & $2.9 *(0.2)$ & $2.7 *(0.5)$ & $2.6 *(0.3)$ & $2.2 *(0.4)$ \\
\hline Distance 2 & $-0.6 *(0.1)$ & $-0.6 *(0.1)$ & $-1.0^{*}(0.1)$ & $-1.2^{*}(0.2)$ & $-1.4^{*}(0.3)$ & $-0.9(0.5)$ & $-1.1 *(0.1)$ & $-1.3 *(0.4)$ \\
\hline Sex similarity & $1.1 *(0.3)$ & $0.9 *(0.1)$ & $1.1 *(0.3)$ & $0.6^{*}(0.1)$ & $0.6^{*}(0.2)$ & $0.9(0.5)$ & $0.9^{*}(0.2)$ & $1.1 *(0.5)$ \\
\hline \multicolumn{9}{|c|}{ Tie formation confluence } \\
\hline $\mathrm{AB}$ alter ${ }^{2}$ & $0.06(0.06)$ & $0.05(0.06)$ & $-0.13 *(0.06)$ & $0.01(0.05)$ & $0.34 *(0.07)$ & $0.09(0.09)$ & $-0.21(0.20)$ & $-0.29 *(0.1)$ \\
\hline Rejection ${ }^{b}$ similarity & $0.6 *(0.3)$ & $0.8 *(0.3)$ & $1.3 *(0.3)$ & $0.6(0.7)$ & $1.4 *(0.4)$ & $0.8^{\star}(0.3)$ & $1.6(1.0)$ & $0.7(0.6)$ \\
\hline $\mathrm{AB}$ average alter & $1.0(0.6)$ & $0.1(0.4)$ & $0.2(0.3)$ & $-0.1(0.6)$ & $-0.2(0.5)$ & $0.8(0.5)$ & $1.3 *(0.5)$ & $0.3(0.7)$ \\
\hline
\end{tabular}

Note: Parameter estimates can be interpreted like coefficients in a multinomial logit regression, reflecting the increase ( + ) or decrease ( - ) in log-odds of a tie forming for the link-formation part of the model (all effects but the last) and of a one-unit increase (decrease) in antisocial behavior for the behavior part of the model (the AB Average Alter effect only).

aff $(+)$, implies ties are more likely to form with more antisocial alters; if $(-)$, they are less likely to form.

bI $(+)$, ties are more likely to form between individuals who have a similar level of rejection; if $(-)$, similar rejection implies ties are less likely to form.

II $(+)$, an individual tends to increase his or her level of antisocial behavior at time $t+1$ the more antisocial his direct-connect alters were at time $t$; if $(-)$, the tendency is to decrease such behavior the more antisocial one's direct conmect alters. 
schools. Outdegree was typically negative and slightly smaller in absolute value than reciprocity; together these parameters suggest that reciprocated (but not asymmetric) ties are likely to form at a rate slightly higher than chance. The negative distance- 2 effects indicate a tendency towards "network closure" for ties to link back on themselves to form cycles. Finally, the well-known preference for same-gender friends among early adolescents is reflected in the generally significant "sex similarity" effects; only one school was found to have a nonsignificant gender effect, and in that school it was trend-significant $(p<.10)$.

The last three rows of Table 6.2 address confluence hypotheses 1,2, and 3. Hypothesis 1 stated that antisocial youth should be socially marginalized, which we tested by including an effect of $A B$-alter in each model. This parameter should be significant and negative if hypothesis 1 is correct. In schools 3 and 8 , we see this confirmed, but effects are nonsignificant in 1, 2, 4, 6, and 7 . In school 5 , the effect is significant but positive: ties are more likely to extend to the antisocial youth. This is clearly the opposite of hypothesis 1 but consistent with other findings related to ecological variation in how antisocial youth affiliate with peers (for example, Stormshak et al., 1999).

Hypothesis 2 implies that rejected youth (often nominated as disliked) tend to affiliate disproportionately with each other. A significant rejection confluence effect appears in five schools, with positive trends in the other three, providing compelling support for rejection confluence in that students form into subgroups based on similar experiences with respect to marginalization within their schools.

Finally, hypothesis 3 states that youth who affiliate with more AB-alters will tend to have higher antisocial behavior scores in the next wave. However, the effect appeared in only school 7.

\section{Discussion}

The confluence model proposes that rejection by peers influences peer networks by means of high risk youth aggregating into cliques, which then later influences the development of antisocial behavior, especially in adolescence. This simple hypothesis has been difficult to test comprehensively, largely because of the complex methodological issues inherent in analyzing changing networks over time.

The agent-oriented SIENA modeling approach, however, provided a natural framework for such a test. In our analyses, we examined each school as its own ecology. We found universal support for the hypothesis that rejected children tend to affiliate over time. Antisocial youth, however, were not always peer rejected. Consistent with the findings of others, in some schools, antisocial behavior was associated with acceptance and even popularity (for example, Rodkin et al., 2000; Rodkin, Farmer, Pearl, \& Van Acker, 2006). Finally, we found evidence that antisocial affiliation predicted subsequent growth in antisocial behavior - that is, influence-in only one middle school. 
Clearly it was useful to analyze each school separately, as it seems that each school presents with unique network dynamics. From a substantive perspective, it is evident that the confluence hypothesis can only account for peer-level antisocial homophily and the growth of antisocial behavior over time in one of these eight schools. What is to be made of these results?

We suggest three potentially productive directions for future research. First, of course it may turn out that the endogenous growth of antisocial behavior is relatively rare, occurring only under certain special conditions. If true, this would not be uninteresting - hundreds or thousands of middle schools nationwide may be unwittingly structured to allow this type of pathological process. Therefore, one fruitful approach is to study antisocial peer processes within and across specific school ecologies. Multilevel designs can potentially disentangle school-level effects (neighborhood, composition, administrative procedures) versus cohort composition effects, either or both of which might account for this variation. For example, we might find that schools with low overall levels of peer rejection confluence also exhibit less peer influence on antisocial behavior. Perhaps in those ecologies, the only sources of growth in such behavior are exogenous.

Second, given ancillary evidence of the ubiquity of social influence among adolescents, it is altogether possible that to detect such effects in natural settings, much better data are required. Frequent assessments of peer relationships and behaviors are required to accurately observe which changes seem to be causes (having occurred earlier in time) and which are effects (having occurred later). As the interval between observations increases, more of these events will appear to be "ties," that is, both occurring in the same time period. Ties are uscless as evidence for whether affiliation caused behavior (influence) or behavior caused affiliation (selection). The yearly assessment strategy used in this study may be inadequate to the task. The same point may apply to other network-based studies that found weak or absent influence effects (see Engels, Vitaro, Den Exter Blokland, de Kemp, \& Scholt, 2004; Ennett \& Bauman, 1994; Jaccard, Blanton, \& Dodge, 2005).

Third, we suggest that social networking research be linked at some point with direct observation research. We know from direct observation studies that deviancy training as observed with a "friend" at age thirteen predicts growth in multiple forms of problem behavior well into adulthood (for example, Dishion, Nelson, Winter \& Bullock, 2004). Often youth identified as friends are not part of the school environment or even especially close. Rather, they are more nearly "regular associates," peers with whom the child spends a great deal of time. Thus, some peer environments may promote influence, but not necessarily from friendships as defined in previous studies. Adapting the types of observational methods used with smaller groups of high-risk children (for example, Dishion, Poulin, \& Burraston, 2001) to larger peer social ecologies could help identify some of these mechanisms and the contexts in which they arise. 
Nevertheless, even if only some school social ecologies unwittingly promote the growth of antisocial behavior or other behavior problems, it is important to continue to develop our research methods to help engineer less contagion-prone environments. Every teacher and principal knows that cohorts of students can vary dramatically in their levels of problem behavior even within one school. Giving adults better tools to manage peer environments would help students with learning and character development and school staff with teaching environment and stress. Festinger, Schachter, and Back (1950) found that relationships between individuals are less likely when the opportunity for chance encounters is lower; sy5tematically separating at-risk youth (contrary to much current practice) or lessening their opportunities for unsupervised interaction provide possible examples. Nevertheless, we must be able to reliably predict the absence and the presence of key dynamics before this strategy can be reliably implemented, underscoring the critical importance of more powerful research designs.

\section{References}

Bauman, K. E., \& Fisher, L. A. (1986). On the measurement of friend behavior in research on friend influence and selection: Findings from longitudinal studies of adolescent smoking and drinking. Journal of Youth and Adolescence, 15, 345-53.

Biglan, A., Metzler, C. W., \& Ary, D. V. (1994). Increasing the prevalence of successful children: The case for community intervention research. Behavior Analyst, 17, 335-51.

Butner, J., Amazeen, P. G., \& Mulvey, G. M. (2005). Multilevel modeling of two cyclical processes: Extending differential structural equation modeling to nonlinear coupled systems. Psychological Methods, 10(2), 159-177.

Cairns, R. B., Neckerman, H. J., \& Caims, B. D. (1989). Social networks and the shadows of synchrony. In G. P. Adams, R. Montemayor, \& T. P. Gullotta (Eds.), Biology of adolescent behavior and development (pp. 275-303). Thousand Oaks, CA: Sage.

Coie, J. D., \& Kupersmidt, J. B. (1983). A behavioral analysis of emerging social status in boys groups. Child Development, 54, 1400-1416.

Dishion, T. J., Nelson, S. E., \& Kavanagh, K. (2003). The family check-up with highrisk young adolescents: Preventing early onset substance use by parent monitoring. Behavior Therapy, 34, 553-571.

Dishion, T. J., Nelson, S. E., Winter, C., \& Bullock, B. M. (2004). Adolescent friendship as a dynamic system: Entropy and deviance in the etiology and course of antisocial behavior. Journal of Abnormal Child Psychology, 32, 651-663.

Dishion, T. J., Nelson, S. E., \& Yasui, M. (2005). Predicting early adolescent gang involvement from middle school adaptation. Journal of Clinical Child and Adolescent Psychology, 34(1), 62-73.

Dishion, T. J., \& Patterson, G. R. (2006). The development and ecology of antisocial behavior. In D. Cicchetti \& D. J. Cohen (Eds.), Developmental psychopathology. Vol. 3: Risk, disorder, and adaptation (pp. 503-541). Hoboken, NJ: Wiley.

Dishion, T. J., Patterson, G. R., \& Griesler, P. C. (1994). Peer adaptations in the devel opment of antisocial behavior: A confluence model. In L. R. Huesmann (Ed.), Aggressive behavior: Current perspectives (pp. 61-95). New York: Plenum.

Dishion, T. J., Poulin, F., \& Burraston, B. (2001). Peer group dynamics associated with iatrogenic effects in group interventions with high-risk youth (pp. 79-92). In C. Erdly 
\& D. W. Nangle (Eds.), Damon's new directions in child development: The role of friendship in psychological adjustment. San Francisco: Jossey-Bass.

Dodge, K. A. (1983). Behaviorat antecedents: A peer social status. Child Development, 54, $1386-1399$.

Dodge, K. A, Lansford, J. E., Burks, V. S., Bates, J. E., Pettit, G. S., Fontaine, R., et al. (2003). Peer rejection and social information-processing factors in the development of aggressive behavior problems in children. Child Development, 74(2), 374-m393.

Elliott, D., Huizinga, D., \& Ageton, S. S. (1985). Explaining delinquency and drug use. Thousand Oaks, CA: Sage.

Engels, R.C.M., Vitaro, F., Den Exter Blokland, E., de Kemp, R., \& Scholt, R.H.J. (2004). Influence and selection processes in friendships and adolescent smoking behaviour: The role of parental smoking. Joumal of Adolescence, 27, 531-44.

Ennett, S. T., \& Bauman, K. E. (1994). The contribution of influence and selection to adolescent peer group homogeneity: The case of adolescent cigarette smoking. Journal of Personality and Social Psychology, 67(4), 652-663.

Farmer, T. W., \& Hollowell, J. H. (1994). Social networks in mainstream classrooms: Social affiliations and behavioral characteristics of students with EBD. Joutnal of Emotional and Behavioral Disorders, 2, 143-156.

Farmer, T. W., Van Acker, R. M., Pearl, R., \& Rodkin, P. C. (1999). Social networks and peer-assessed problem behavior in elementary classrooms. Remedial and Special Education, 20(4), 244-256.

Festinger, L., Schachter, S., \& Back, K. (1950). Social pressures in informal groups: A study of human factors in housing. New York: HarperCollins.

Gifford-Smith, M., Dodge, K. A., Dishion, T. J., \& McCord, J. (2005). Peer influence in children and adolescents: Crossing the bridge from developmental to intervention science. Journal of Abnormal Child Psychology, 33(3), 255-265.

Gold, M. (1970). Delinquent behavior in an American city. San Francisco: Brooks \& Coleman.

Hartup, W. W. (1992). Friendships and their developmental significance. In H. McGurk (Ed.), Childhood social development: Contemporary perspectives (pp. 175-205). Mahwah, NJ: Exlbaum.

Jaccard, J., Blanton, H., \& Dodge, T. (2005). Peer influences on risk behavior: An analysis of the effects of a close friend. Developmental Psychology, 41(1), 135-147.

Kenny, D. A., \& Judd, C. M. (1986). Consequences of violating the independence assumption in analysis of variance. Psychological Bulletin, 99, 422-431.

Kessler, R. C., \& Greenberg, D. F. (1981). Linear panel analysis: Models of quantitative change. Orlando, FL: Academic Press.

Marsden, P. V. (2005). Recent developments in network measurement. In P. J. Carrington, J. Scott, \& S. Wasserman (Eds.), Models and methods in social network analysis (pp. 8-30). Cambridge: Cambridge University Press.

Murray, D. M., \& Hannan, P. J. (1990). Planning for the appropriate analysis in schoolbased drug use prevention studies. Journal of Consulting and Clinical Psychology, 58(4), 458-468.

Olson, S. L. (1992). Development of conduct problems and peer rejection in pre-school children: A social systems analysis. Journal of Abnormal Child Psychology, 20, 327-350.

Prinstein, M. J., \& Wang, S. S. (2007). False consensus and adolescent peer contagion: Examining discrepancies between perceptions and actual reported levels of friends' deviant and health risk behaviors. Journal of Abnormal Child Psychology, 33(3), 293-306.

Rodkin, P. C., Farmer, T. W., Pearl, R., \& Van Acker, R. M. (2000), Heterogeneity of popular boys: Antisocial and prosocial configurations. Developmental Psychology, 36, 14-24.

Rodkin, P. C., Farmer, T. W., Pearl, R., \& Van Acker, R. M. (2006). They're cool: Social status and peer group supports for aggressive boys and girls. Social Development, $15(2), 175-204$ 
Snijders, T.A.B. (2001). The statistical evaluation of social network dynamics. In M. E. Sobel \& M. P. Becker (Eds.), Sociological methodology. Boston: Basil Blackwell.

Snijders, T.A.B. (2005). Models for longitudinal network data. In P. J. Carrington, J. Scott, \& S. Wasserman (Eds.), Models and methods in social network analysis (pp. 215-247). Cambridge: Cambridge University Press.

Snijders, T.A.B., Steglich, C.E.G., \& Schweinberger, M. (2006). Modeling the coevolution of networks and behavior. In K. van Montfort, H. Oud, \& A. Satorra (Eds.), Longitudinal models in the behavioral and related sciences. Mahwah, NJ: Erlbaum.

Snijders, T.A.B., Steglich, C.E.G., Schweinberger, M., \& Huisman, M. (2007). Manual for SIENA version 3. Groningen, The Netherlands: University of Gröningen, ICS, Department of Sociology.

Stormshak, E. A., Dishion, T. J., Light, J., \& Yasui, M. (2005). Implementing familycentered interventions within the public middle school: Linking service delivery to change in problem behavior. Journal of Abnormal Child Psychology, 33, 723-33.

Stormshak, E. A., Bierman, K. L., Bruschi, C., Dodge, K. A., Coie, J., \& the Conduct Problems Research Group (1999). The relation between behavior problems and peer preference in different classroom contexts. Child Development, 70(1), 169-182.

Wasserman, S., \& Faust, K. (1994). Social network analysis: Methods and applications. Cambridge: Cambridge University Press.

JOHN M. LIGHT is associate scientist at the Oregon Research Institute.

THOMAS J. DISHON is professor of psychology and school psychology and the director of the Child and Family Center at the University of Oregon. 